\title{
Temperature dependence of postmortem MR quantification for soft tissue discrimination
}

\author{
Wolf-Dieter Zech • Nicole Schwendener • \\ Anders Persson • Marcel J. Warntjes • \\ Christian Jackowski
}

Received: 6 May 2014 /Revised: 21 October 2014 / Accepted: 8 January 2015 / Published online: 1 February 2015

(C) European Society of Radiology 2015

\begin{abstract}
Objectives To investigate and correct the temperature dependence of postmortem MR quantification used for soft tissue characterization and differentiation in thoraco-abdominal organs.

Material and methods Thirty-five postmortem short axis cardiac 3-T MR examinations were quantified using a quantification sequence. Liver, spleen, left ventricular myocardium, pectoralis muscle and subcutaneous fat were analysed in cardiac short axis images to obtain mean T1, T2 and PD tissue values. The core body temperature was measured using a rectally inserted thermometer. The tissue-specific quantitative values were related to the body core temperature. Equations to correct for temperature differences were generated.

Results In a 3D plot comprising the combined data of T1, T2 and $\mathrm{PD}$, different organs/tissues could be well differentiated from each other. The quantitative values were influenced by the temperature. $\mathrm{T} 1 \mathrm{in}$ particular exhibited strong temperature dependence. The correction of quantitative values to a temperature of $37^{\circ} \mathrm{C}$ resulted in better tissue discrimination.

Conclusion Postmortem MR quantification is feasible for soft tissue discrimination and characterization of thoracoabdominal organs. This provides a base for computer-aided diagnosis and detection of tissue lesions. The temperature dependence of the T1 values challenges postmortem MR quantification. Equations to correct for the temperature dependence are provided.
\end{abstract}

W.-D. Zech $(\bowtie) \cdot$ N. Schwendener $\cdot$ C. Jackowski

From the Institute of Forensic Medicine, University of Bern,

Buehlstrasse 20, 3012 Bern, Switzerland

e-mail: Wolf-Dieter.Zech@irm.unibe.ch

A. Persson · M. J. Warntjes

The Center for Medical Image Science and Visualization (CMIV),

University of Linköping, 58185 Linköping, Sweden
Key points

- Postmortem MR quantification is feasible for soft tissue discrimination and characterization

- Temperature dependence of the T1 values challenges the MR quantification approach

- The results provide the basis for computer-aided postmortem MRI diagnosis

- Diagnostic criteria may also be applied for living patients

Keywords Postmortem magnetic resonance imaging · Quantitative MRI · MRI temperature dependence · Soft tissue · Thoraco-abdominal organs

$\begin{array}{ll}\text { Abbreviations } \\ \text { MRI } & \text { Magnetic resonance imaging } \\ \text { PD } & \text { Proton density } \\ \text { pmMRI } & \text { Postmortem resonance imaging } \\ \text { ROI } & \text { Region of interest } \\ \text { T } & \text { Tesla } \\ \text { TE } & \text { Echo time } \\ \text { TR } & \text { Repetition time } \\ \text { T2w } & \text { T2-weighted }\end{array}$

\section{Introduction}

Postmortem MRI (pmMRI) has become a valuable tool for non-invasively documenting forensic and pathological findings in the deceased [1-5]. Soft tissue pathology can be conducted in cross sections thinner than possible in any routine autopsy and in any geometrical plane [6-12]. However, MR imaging of a deceased body is far different from clinical MRI, and interpreting postmortem, unenhanced MR images requires special expertise [13-15]. 
Certain circumstances challenge postmortem MR image acquisition and interpretation, such as different corpse temperatures at examination, causing changing tissue contrasts within the images. An approach to overcome this problem is to synthetically calculate MR images using individually optimized parameters, such as echo time (TE), repetition time (TR) and inversion time (TI). This approach is based on a recently implemented MR sequence that allows for a rapid quantification of relaxation times and proton density (PD) using a twin-echo saturation-recovery turbo spin echo acquisition $[16,17]$. During a multi-slice saturation-recovery turbo spin echo (TSE) sequence, each excitation is followed by two separate echo acquisitions. This allows for a simultaneous detection of $T_{1}$ and the $T_{2}$ relaxation times independently of each other. As soon as $T_{1}$ and $T_{2}$ are known, the combination allows for a calculation of the absolute signal intensity at $\mathrm{TE}=$ $0 \mathrm{~ms}$ and $\mathrm{TI}=$ infinite, equal to the PD. All three parameters can be measured in a single acquisition, which avoids rescaling differences that occur in methods that use several images in combination (Fig. 1). Independent determination of $T_{1}$ and $T_{2}$ prevents error propagation, whereas in methods using consecutive measurements, determining the second parameter based on the first parameter, error propagation is a common problem. Furthermore the maps are inherently coregistered. Additionally, the sequence allows the actual local flip angle to be calculated. This calculation adds robustness compared with other alternatives requiring an additional B1 mapping for local flip-angle correction [17].

On the basis of this acquisition and determining the relaxation times and PD in a certain region of interest (ROI), any tissue contrast image with a certain combination of TE and TR or pre-pulses may be synthetically reconstructed using an additional post-processing step. The synthetic images aid in radiologically recognizing the imaged anatomy, since they are

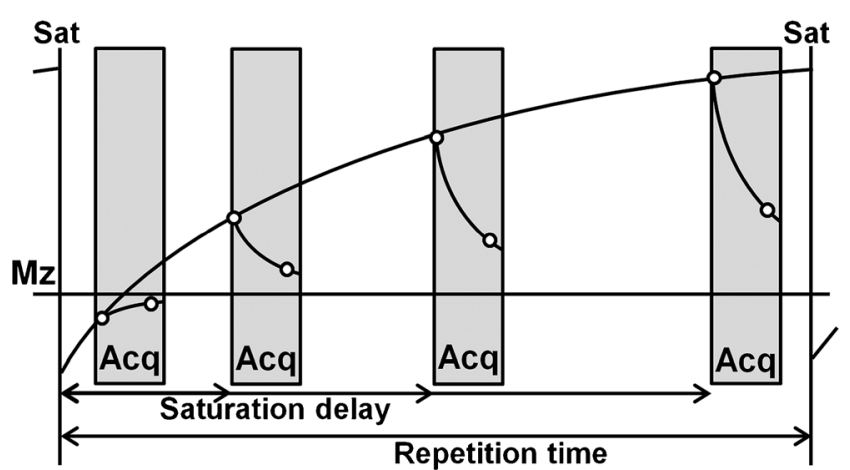

Fig. 1 Schematic overview of the applied quantification sequence. In order to measure $\mathrm{T} 1$ and $\mathrm{T} 2$ relaxation and proton density (PD) a saturation pulse (Sat) is applied at each repetition time TR to decrease the longitudinal magnetization Mz. At 4 different saturation delay times the signal is acquired where each acquisition consists of a dual echo read-out (white dots). Hence the acquisition generates a matrix of $4 \times 2$ images where signal strength is proportional to the magnetization at various saturation delays and echo times. A least-square minimization algorithm finds the optimal T1, T2 and PD values for each pixel similar to conventional MR images without relevant loss of image quality. The quantified parameters $\mathrm{T} 1, \mathrm{~T} 2$ and PD are not vendor specific and can be used to characterize soft tissues in an objective manner by measuring and comparing three different parameters. MRI is commonly used to assess different image contrasts at different imaging parameter settings. By quantifying the tissues and lesions, tissue alterations of different individuals become comparable which provides a basis for automatic tissue recognition and computer-aided diagnostics [16-21]. The purpose of the present study was to investigate and correct for the temperature dependence of postmortem MR quantification used for soft tissue characterization and differentiation in thoraco-abdominal organs, thus providing the basis for contrast optimization efforts, with respect to the broad temperature ranges of corpses.

\section{Material and methods}

In forensic cases $(n=35)$, a quantification sequence was added to a postmortem cardiac 3-T MR examination (Achieva, Philips Healthcare, Best, the Netherlands) [11, 12]. The examinations were performed at the Institute of Forensic Medicine, University of Zürich, Switzerland. The age at death ranged from 11 to 94 years (mean 52 years, SD 18.3). In all cases, a forensic autopsy was ordered by the local authorities. The MR examination was performed prior to autopsy. Board-certified forensic pathologists performed the autopsy directly after imaging or the following morning. The postmortem interval (time from death to imaging) ranged from several hours to 3 days. Relevant putrefaction gas formation was ruled out using whole-body computed tomography prior to pmMRI to avoid image artefacts. The corpses were wrapped in an artefact-free body bag, a linen sheet or plastic foil. All subjects were examined in supine position. The MRI examination time was $2 \mathrm{~h}$, of which the quantification sequence lasted $15 \mathrm{~min}$. Twenty to 24 short axis slices $4 \mathrm{~mm}$ in thickness were acquired with a gap of $0.3 \mathrm{~mm}$. The use of the image data for the present study was approved by the local ethics committee.

A commercially available post-processing tool (SyMRI Autopsy, SyntheticMR, Linköping, Sweden) [22] was used to measure the $\mathrm{T} 1$ and $\mathrm{T} 2$ relaxation times and PD by placing five ROIs in organs (myocardium, liver, spleen) and tissues (subcutaneous fat and pectoralis muscle) covered on cardiac short axis images (Fig. 2). T1 and T2 relaxation times in milliseconds (ms) as well as the PD (\%) were plotted in a 3D plot using the ThreeDifyExcelGrapher add-in for Microsoft Excel $^{\circledR}$ to investigate clustering and separation of organs and tissues. Two-way analysis of variance (ANOVA) was carried out to look for significant differences of quantitative T1, T2 and $\mathrm{PD}$ values between all organs/tissues. The null hypothesis was rejected when the $p$ value was less than 0.05 . 
Fig. 2 Cardiac short axis synthetically calculated T1w MRI image. Quantitative values (red box) of myocardium, liver, spleen, pectoralis muscle and subcutaneous fat were obtained by placing ROIs (yellow arrow, measurement illustrated for the heart) into organs/tissues

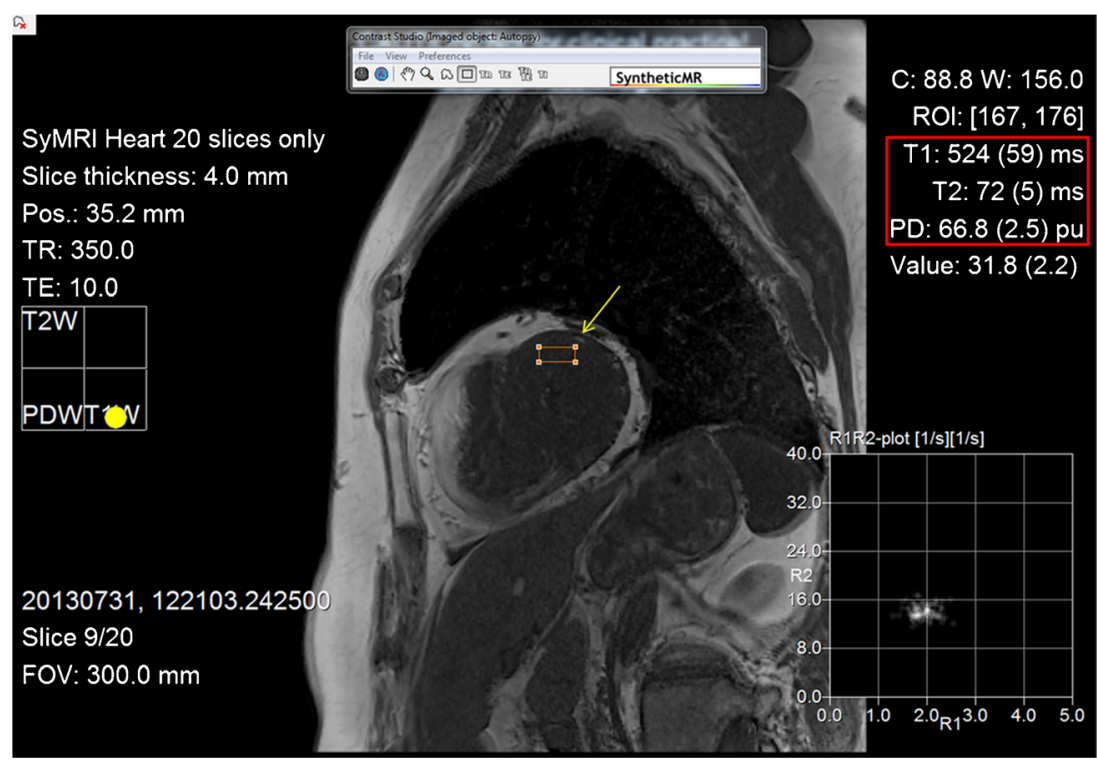

For evaluating the temperature of thoraco-abdominal organs and tissues the rectal temperature was measured prior to and after pmMR examination. The temperatures of corpses ranged from 7 to $32^{\circ} \mathrm{C}$ (mean temperature $16.8^{\circ} \mathrm{C}, \mathrm{SD} 7.3$ ). Linear interpolation to the time of acquisition of the quantification sequence provided an estimation of the core body temperature at imaging. The quantitative values for T1, T2 and $\mathrm{PD}$ of each investigated organ/tissue were plotted and related to the body core temperature of the corpse at the time of data acquisition.

Linear equations were generated using Microsoft Excel ${ }^{\circledR}$ to assess the T1/temperature, T2/temperature and PD/ temperature relationships for each investigated organ. Those equations were used to correct the values of T1, T2 and PD for all investigated organs/tissues to a temperature of $37^{\circ} \mathrm{C}$. The T1, T2 and PD values not corrected for temperature were compared to the values corrected to $37{ }^{\circ} \mathrm{C}$ using the $F$ test for equality of variances with Microsoft Excel ${ }^{\circledR}$.

\section{Results}

Quantitative values/temperature relations as obtained in the investigated cases were expressed by linear equations. Table 1 lists the linear equations generated for each investigated organ/tissue. Individual variation of the relation between the change of temperature and change of quantitative values was observed in all organs/tissues. A temperature dependence was observed mainly for the $\mathrm{T} 1$ values that increased with rising temperature in all investigated organs/tissues, as illustrated for the heart in Fig. 3. T2 and PD values were only slightly influenced by temperature in all organs/tissues.

Table 2 shows the mean quantitative values (T1 and T2 relaxation times as well as the $\mathrm{PD}$ ) obtained for all examined organs/tissues in 35 cases that were correlated with body temperature. Quantitative values were plotted in a $3 \mathrm{D}$ coordinate system and are depicted as corrected for a temperature of $37{ }^{\circ} \mathrm{C}$ (Fig. 4a) and not corrected for temperature (Fig. 4b). In the $3 \mathrm{D}$ plot the clusters of myocardium, liver, spleen, pectoralis muscle and subcutaneous fat can be easily discriminated from each other. A significant difference between the quantitative values of all organs/ tissues could be observed in the ANOVA. A greater significance between all organs/tissues was observed for the quantitative values that were corrected to $37{ }^{\circ} \mathrm{C}$ (Table 3 ). Comparison of the $\mathrm{T} 1$ and $\mathrm{T} 2$ values that were corrected to $37{ }^{\circ} \mathrm{C}$ with $\mathrm{T} 1$ and $\mathrm{T} 2$ relaxation times for $3-\mathrm{T}$

Table 1 Linear equations for all investigated organs/tissues generated from the relation of T1 and T2 time as well as PD to core temperature at the time of scanning as obtained in 35 forensic cases

\begin{tabular}{llllll}
\hline & Myocardium & Liver & Spleen & Pectoralis muscle & Subcutaneous fat \\
\hline$T_{1}$ temperature & $T_{1}=13.285 T+709.48$ & $T_{1}=11.026 \mathrm{~T}+449.13$ & $T_{1}=16.557 T+578.33$ & $T_{1}=8.6567 T+628.95$ & $T_{1}=4.347 T+283.16$ \\
$T_{2} /$ temperature & $T_{2}=0.0443 T+60.52$ & $T_{2}=0.2737 T+32.502$ & $T_{2}=0.0188 T+36.558$ & $T_{2}=-0.3543 T+58.615$ & $T_{2}=1.439 T+43.385$ \\
PD/temperature & $\mathrm{PD}=0.1521 T+69.20$ & $\mathrm{PD}=0.0389 T+71.015$ & $\mathrm{PD}=-0.6106 T+67.768$ & $\mathrm{PD}=-0.0002 T+68.869$ & $\mathrm{PD}=1.2116 T+104.39$ \\
\hline
\end{tabular}

$T_{1} \mathrm{~T} 1$ relaxation time in milliseconds, $T_{2} \mathrm{~T} 2$ relaxation time in milliseconds, $T$ body core temperature in ${ }^{\circ} \mathrm{C}, P D \mathrm{PD}$ in $\%$ related to pure water $(100 \%)$ 

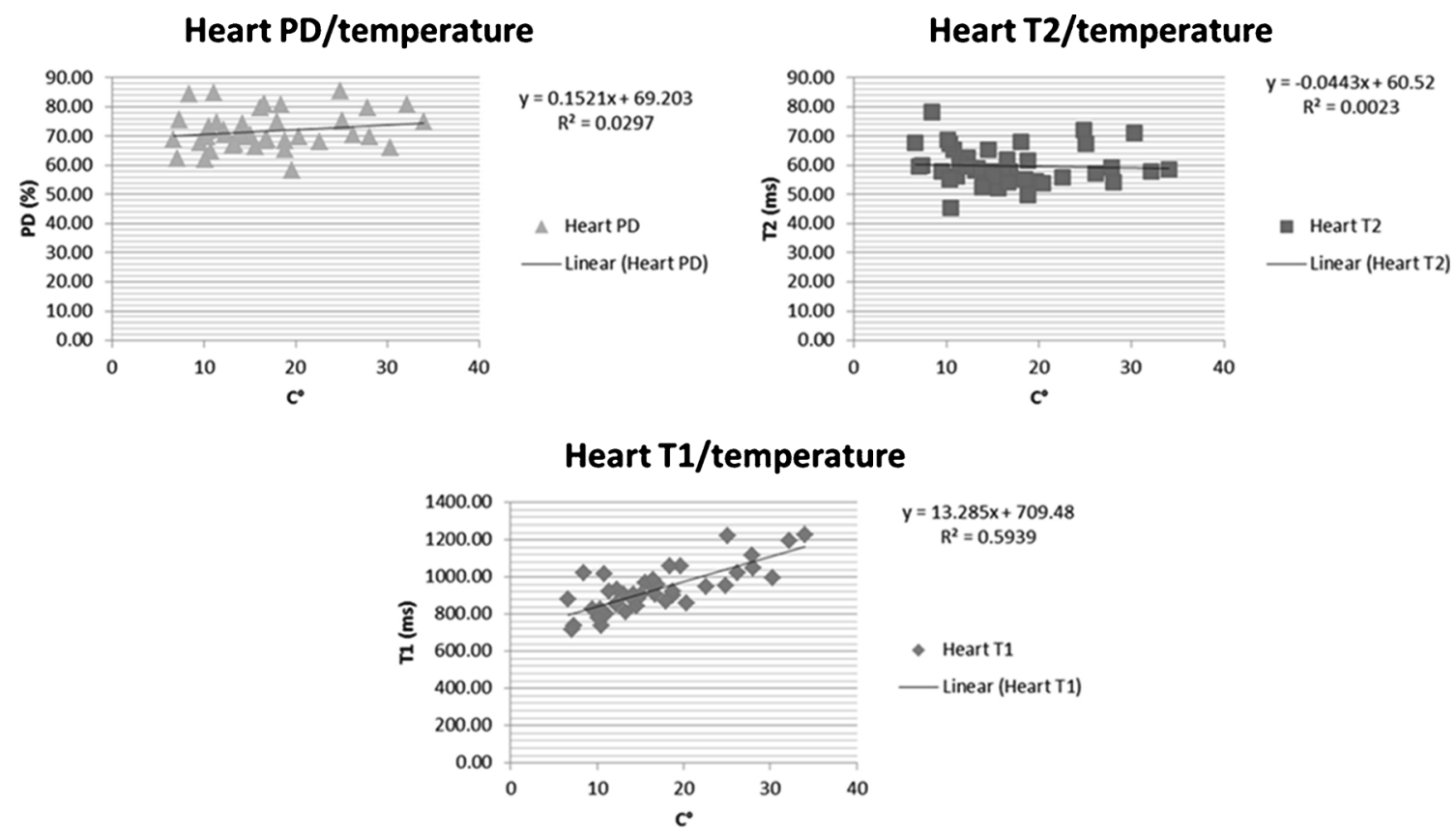

Fig. 3 Plots of myocardial T1 and T2 relaxation times and PD vs. body core temperature at the time of scanning. Note that a strong temperature dependence is observed for the $\mathrm{T} 1$ values only

applications collected from the literature showed that the ex vivo values from the present study are within the range of the known in vivo values (Table 2). In the current literature there were no quantitative PD values or quantitative T1 and T2 values for pectoral muscles [23-27].

Table 4 shows the results from the $F$ test that was performed to compare the variances of the distributions from the means of $\mathrm{T} 1, \mathrm{~T} 2$ and PD values not corrected for temperature and the quantitative values corrected for $37{ }^{\circ} \mathrm{C}$ for every single organ/tissue. In every organ/tissue the values corrected to $37{ }^{\circ} \mathrm{C}$ exhibit a slightly lower standard deviation yet the variances of distributions from the mean values corrected to $37{ }^{\circ} \mathrm{C}$ did not differ significantly compared to those of the uncorrected values within the single organs/tissues.

\section{Discussion}

Synthetic MRI sequences allow for simultaneous determination of T1 and T2 tissue relaxation times as well as for tissue PD [16-19]. In the present postmortem study, the synthetic MRI approach was applied for the first time to investigate different thoraco-abdominal organs and tissues. The investigated organs and tissues could be differentiated from each other by their quantitative values of T1, T2 and PD. This provides the basis for additional promising applications of quantitative MRI. Databases for quantitative values of T1, T2 and PD of normal organ tissues as well as of pathologic tissues can be established. As a result, a scale of quantitative values for tissue lesions and normal tissue can be created similar to the Hounsfield scale in CT applications, only with

Table 2 Mean quantification values ( $\mathrm{T} 1$ and $\mathrm{T} 2$ in ms; PD in \%) obtained from different organs/tissues in 35 forensic cases

\begin{tabular}{|c|c|c|c|c|c|c|c|c|}
\hline & $\begin{array}{l}\text { T1 uncorrected } \\
\text { (SD) }\end{array}$ & $\begin{array}{l}\text { T1 corrected to } \\
37^{\circ} \mathrm{C} \text { (SD) }\end{array}$ & $\begin{array}{l}\mathrm{T} 1 \text { in vivo } \\
\text { (literature) }\end{array}$ & $\begin{array}{l}\mathrm{T} 2 \\
\text { uncorrected } \\
(\mathrm{SD})\end{array}$ & $\begin{array}{l}\mathrm{T} 2 \text { corrected } \\
\text { to } 37^{\circ} \mathrm{C}(\mathrm{SD})\end{array}$ & $\begin{array}{l}\text { T2 in vivo } \\
\text { (literature) }\end{array}$ & $\begin{array}{l}\text { PD } \\
\text { uncorrected } \\
\text { (SD) }\end{array}$ & $\begin{array}{l}\text { PD corrected } \\
\text { to } 37^{\circ} \mathrm{C} \text { (SD) }\end{array}$ \\
\hline Myocardium & $938.93(129.1)$ & $1,199.95$ (95.33) & $1,187-1,274$ [23] & $59.46(6.39)$ & $60.33(6.39)$ & $36-59[24]$ & $71.65(8.16)$ & $74.63(8.03)$ \\
\hline Liver & $680.09(107.62)$ & $896.72(90.82)$ & $809 \pm 71[25]$ & $36.95(7.9)$ & $42.32(7.65)$ & $34 \pm 4[25]$ & $71.48(3.74)$ & $72.25(3.72)$ \\
\hline Spleen & $931.84(207.66)$ & $1,257.14(192.47)$ & $1,221 \pm 62[26]$ & $36.75(7.53)$ & $37.12(7.53)$ & $34 \pm 5.9[26]$ & $56.39(10.24)$ & $44.39(9.4)$ \\
\hline Pectoralis muscle & $828.62(75.97)$ & 998.7 (70.92) & NA & $51.8(5.73)$ & $44.84(5.49)$ & NA & $68.33(8.81)$ & $68.33(8.81)$ \\
\hline Subcutaneous fat & $384.41(33.55)$ & $468.84(30.94)$ & $382 \pm 13[25]$ & $68.23(13.57)$ & $96.18(6.97)$ & $41-143$ [27] & $124.6(18.61)$ & $148.13(16.32)$ \\
\hline
\end{tabular}

Quantitative values are shown as corrected for a temperature of $37^{\circ} \mathrm{C}$ and not corrected for temperature. Note the slight decrease of standard deviations for the values corrected to $37^{\circ} \mathrm{C}$ in most organs. $\mathrm{T} 1$ and $\mathrm{T} 2$ values that were corrected to $37^{\circ} \mathrm{C}$ were within the range of in vivo $\mathrm{T} 1$ and $\mathrm{T} 2$ relaxation times collected from the literature (in vivo data for PD values or quantitative T1 and T2 values for pectoral muscles were not available, NA) 
a

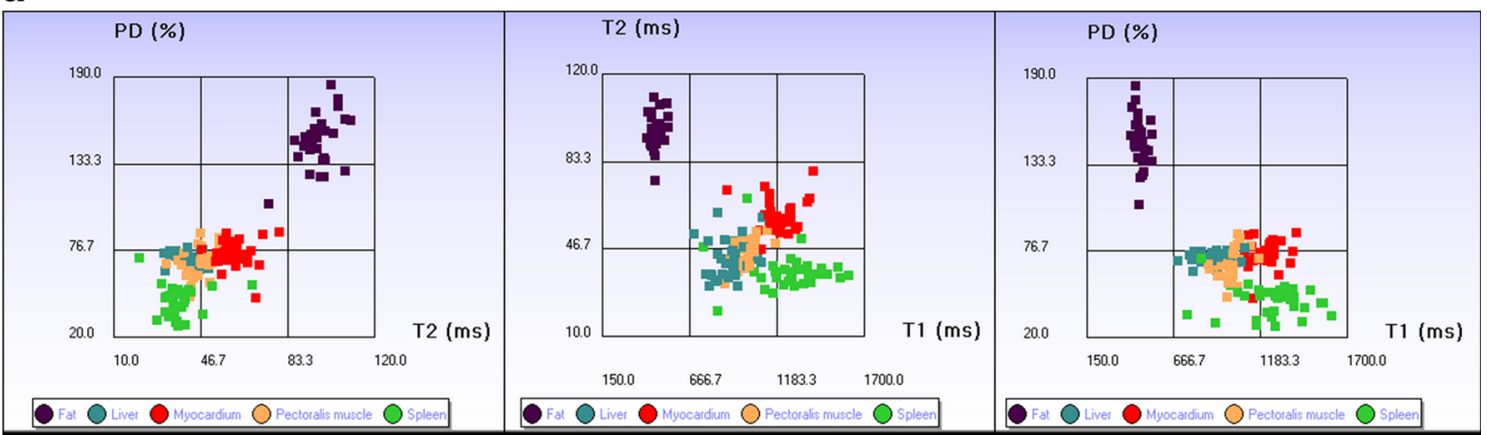

b

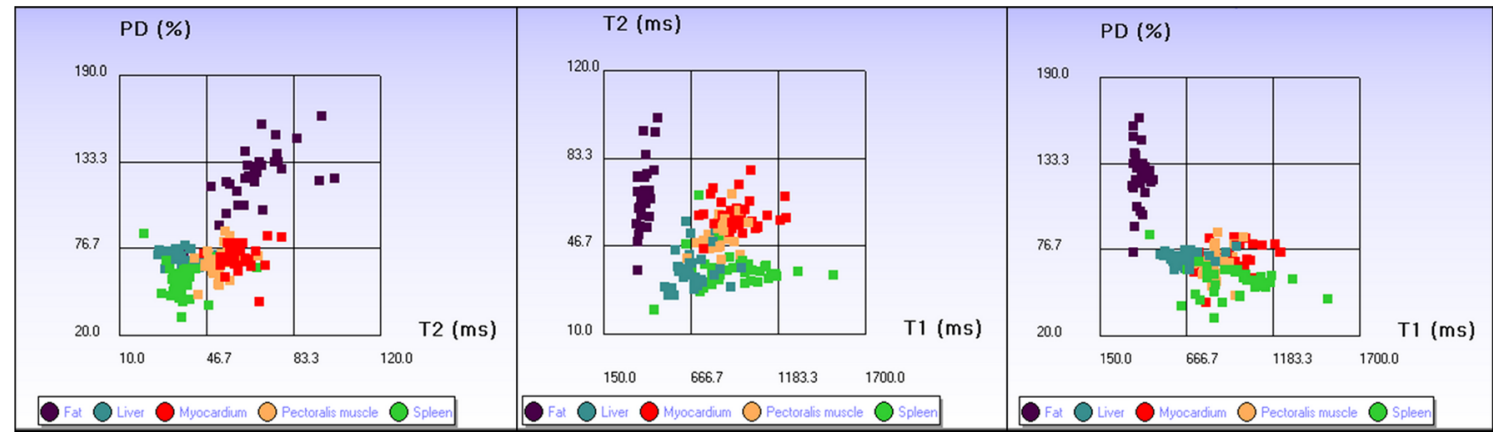

Fig. 4 Three defined views (PD/T2 view, T2/T1 view and PD/T1 view) on a 3D plot of different tissues based on $\mathrm{T} 1$ and $\mathrm{T} 2$ relaxation times and PD. Values are depicted as corrected for a temperature of $37^{\circ} \mathrm{C}$ (a) and not corrected for temperature (b). Note that the clusters of different

a far greater potential of soft tissue analysis and discrimination [20]. Using quantitative data from synthetic MRI applications also provides the basis for automatic tissue detection and pathologic tissue detection approaches. Synthetic MRI images can be loaded on a personal computer with recently developed software. Computer-aided diagnostics can be implemented on the basis of established ranges of the signal behaviour of normal postmortem tissue and pathological alterations. Pathologic tissue can, for example, automatically be detected and encoded in different colours. On one hand, this can help the image reader to detect pathologic tissue; on the other hand, information regarding the nature of the pathologic area can also be obtained. It can be speculated that the use of synthetic MRI can overcome the shortcoming of the rather insufficient soft tissue analysis in forensic postmortem imaging. The more commonly used postmortem CT is a useful tool, for example, in detecting gas or bone lesions. However, it is unsatisfactory for adequate soft tissue analysis and discrimination $[3,4,11$, 20]. The combined use of postmortem CT and postmortem quantitative MRI in routine forensic casework promises to reveal more substantial information on forensic-relevant soft tissue pathologies than so far possible. Synthetic MRI offers the potential of detecting soft tissue lesions, such as oedema, inflammation, infarction, degeneration and tumour lesions. Jackowski et al. demonstrated that it is also possible to organs/tissues can be easily differentiated from each other. Values corrected for a temperature of $37{ }^{\circ} \mathrm{C}$ depicted slightly tighter clustering with less overlapping (seen best in fat tissue) than those not corrected

specifically enhance haemorrhages [20]. Warntjes et al. and Vågberg et al. demonstrated using synthetic MRI in vivo that inflammatory multiple sclerosis lesions in the brain can be differentiated from normal healthy brain tissue by their quantitative T1, T2 and PD values [17, 21]. Further studies are required to reveal the factual diagnostic possibilities and limits of postmortem synthetic MRI for soft tissue analysis.

Quantified isotropic MRI data allow not only for measuring quantitative values of relaxation times and change of image contrast but also for reformatting and image plane reconstruction. Upon manuscript submission, there was no available software that combined all visualization possibilities of synthetic MRI. However, the final goal at the publication's host institute is to establish a forensically optimized workstation for CT and MRI data sets that allows for automatic tissue detection, image plan reconstruction and volume rendering on regular radiological workstations [20, 28, 29].

The temperature dependence of the quantitative values challenges the postmortem synthetic MRI approach. In the present study temperature dependence for the $\mathrm{T} 1$ relaxation time in all examined tissues was observed and investigated. Preliminary studies demonstrated a temperature dependence of T1 relaxation times in blood and living tissue [30-33]. It was shown that the $\mathrm{T} 1$ relaxation time correlated linearly with rising temperature. Our data confirm these examination 
Table 3 Results of the two-way analysis of variance (ANOVA) for comparison of quantitative values for T1 (ms), T2 (ms) and PD (\%) between all organs in 35 forensic cases

\begin{tabular}{|c|c|c|c|c|c|c|c|}
\hline & & $\begin{array}{l}\mathrm{T} 1 \text { not } \\
\text { corrected }\end{array}$ & $\begin{array}{l}\mathrm{T} 2 \text { not } \\
\text { corrected }\end{array}$ & $\begin{array}{l}\text { PD not } \\
\text { corrected }\end{array}$ & $\begin{array}{l}\mathrm{T} 1 \text { corrected } \\
\text { to } 37^{\circ} \mathrm{C}\end{array}$ & $\begin{array}{l}\mathrm{T} 2 \text { corrected } \\
\text { to } 37^{\circ} \mathrm{C}\end{array}$ & $\begin{array}{l}\text { PD corrected } \\
\text { to } 37^{\circ} \mathrm{C}\end{array}$ \\
\hline \multirow[t]{4}{*}{ Myocardium-liver } & Test value & 214.87 & 224.82 & 0.02 & 312.20 & 150.18 & 3.48 \\
\hline & $p$ value & $<0.005$ & $<0.005$ & $>0.05$ & $<0.005$ & $<0.005$ & $>0.05$ \\
\hline & Threshold value & 4.13 & 4.13 & 4.13 & 4.13 & 4.13 & 4.13 \\
\hline & Significance & Yes & Yes & No & Yes & Yes & No \\
\hline \multirow[t]{4}{*}{ Myocardium-spleen } & Test value & 0.06 & 187.04 & 43.99 & 3.89 & 195.10 & 207.07 \\
\hline & $p$ value & $>0.05$ & $<0.005$ & $<0.005$ & $>0.05$ & $<0.005$ & $<0.005$ \\
\hline & Threshold value & 4.13 & 4.13 & 4.13 & 4.13 & 4.13 & 4.13 \\
\hline & Significance & No & Yes & Yes & No & Yes & Yes \\
\hline \multirow[t]{4}{*}{ Myocardium-pectoralis muscle } & Test value & 25.21 & 27.73 & 2.83 & 96.77 & 118.05 & 10.41 \\
\hline & $p$ value & $<0.005$ & $<0.005$ & $>0.05$ & $<0.005$ & $<0.005$ & $<0.005$ \\
\hline & Threshold value & 4.13 & 4.13 & 4.13 & 4.13 & 4.13 & 4.13 \\
\hline & Significance & Yes & Yes & No & Yes & Yes & Yes \\
\hline \multirow[t]{4}{*}{ Myocardium-subcutaneous fat } & Test value & 686.24 & 9.66 & 197.19 & $1,792.12$ & 537.14 & 429.36 \\
\hline & $p$ value & $<0.005$ & $<0.005$ & $<0.005$ & $<0.005$ & $<0.005$ & $<0.005$ \\
\hline & Threshold value & 4.17 & 4.17 & 4.17 & 4.17 & 4.17 & 4.17 \\
\hline & Significance & Yes & Yes & Yes & Yes & Yes & Yes \\
\hline \multirow[t]{4}{*}{ Liver-spleen } & Test value & 68.65 & 0.02 & 56.58 & 142.29 & 16.69 & 224.71 \\
\hline & $p$ value & $<0.005$ & $>0.05$ & $<0.005$ & $<0.005$ & $<0.005$ & $<0.005$ \\
\hline & Threshold value & 4.13 & 4.13 & 4.13 & 4.13 & 4.13 & 4.13 \\
\hline & Significance & Yes & No & Yes & Yes & Yes & Yes \\
\hline \multirow[t]{4}{*}{ Liver-pectoralis muscle } & Test value & 69.20 & 107.14 & 3.88 & 34.19 & 3.79 & 6.01 \\
\hline & $p$ value & $<0.005$ & $<0.005$ & $>0.05$ & $<0.005$ & $>0.05$ & $>0.05$ \\
\hline & Threshold value & 4.13 & 4.13 & 4.13 & 4.13 & 4.13 & 4.13 \\
\hline & Significance & Yes & Yes & No & Yes & No & Yes \\
\hline \multirow[t]{4}{*}{ Liver-subcutaneous fat } & Test value & 268.32 & 160.67 & 234.08 & 673.92 & $1,023.36$ & 592.96 \\
\hline & $p$ value & $<0.005$ & $<0.005$ & $<0.005$ & $<0.005$ & $<0.005$ & $<0.005$ \\
\hline & Threshold value & 4.17 & 4.17 & 4.17 & 4.17 & 4.17 & 4.17 \\
\hline & Significance & Yes & Yes & Yes & Yes & Yes & Yes \\
\hline \multirow[t]{4}{*}{ Spleen-pectoralis muscle } & Test value & 8.55 & 148.54 & 26.88 & 56.51 & 242.95 & 117.67 \\
\hline & $p$ value & $<0.05$ & $<0.005$ & $<0.005$ & $<0.005$ & $<0.005$ & $<0.005$ \\
\hline & Threshold value & 4.13 & 4.13 & 4.13 & 4.13 & 4.13 & 4.13 \\
\hline & Significance & Yes & Yes & Yes & Yes & Yes & Yes \\
\hline \multirow[t]{4}{*}{ Spleen-subcutaneous fat } & Test value & 205.34 & 145.42 & 330.27 & 471.33 & $1,273.97$ & $1,230.64$ \\
\hline & $p$ value & $<0.005$ & $<0.005$ & $<0.005$ & $<0.005$ & $<0.005$ & $<0.005$ \\
\hline & Threshold value & 4.17 & 4.17 & 4.17 & 4.17 & 4.17 & 4.17 \\
\hline & Significance & Yes & Yes & Yes & Yes & Yes & Yes \\
\hline \multirow[t]{4}{*}{ Pectoralis muscle-subcutaneous fat } & Test value & $1,593.71$ & 35.05 & 387.13 & $2,230.67$ & $2,032.91$ & $1,131.91$ \\
\hline & $p$ value & $<0.005$ & $<0.005$ & $<0.005$ & $<0.005$ & $<0.005$ & $<0.005$ \\
\hline & Threshold value & 4.17 & 4.17 & 4.17 & 4.17 & 4.17 & 4.17 \\
\hline & Significance & Yes & Yes & Yes & Yes & Yes & Yes \\
\hline
\end{tabular}

$\mathrm{T} 1, \mathrm{~T} 2$ and PD values are given corrected to $37^{\circ} \mathrm{C}$ and not corrected for temperature. Note in every case there are at least 2 significantly different centre coordinates. Thus a significant difference between all organs/tissues can be assumed. A higher significance can be assumed for the T1, T2 and PD values corrected to a temperature of $37^{\circ} \mathrm{C}$ because there was an increase in all test values (except the T2 values of the myocardium-liver and liver-pectoralis muscle comparison)

results. As with Youl et al., we did observe that T1 changes also differed between different tissues [34]. As the proton spin behaviour, especially the longitudinal spin-lattice T1 relaxation, is influenced by tissue temperature, it explains the strong 
Table 4 Results of the $F$ test for equality of variances of T1, T2 and PD values in single organs/tissues corrected to $37^{\circ} \mathrm{C}$ and not corrected for temperature in 35 forensic cases

\begin{tabular}{|c|c|c|c|c|c|c|c|c|c|c|}
\hline & \multicolumn{2}{|l|}{ Myocardium } & \multicolumn{2}{|l|}{ Liver } & \multicolumn{2}{|l|}{ Spleen } & \multicolumn{2}{|c|}{ Pectoralis muscle } & \multicolumn{2}{|c|}{ Subcutaneous fat } \\
\hline & $\begin{array}{l}R \\
\text { uncorrected }\end{array}$ & $\begin{array}{l}R \\
\text { corrected }\end{array}$ & $\begin{array}{l}R \\
\text { uncorrected }\end{array}$ & $\begin{array}{l}R \\
\text { corrected }\end{array}$ & $\begin{array}{l}R \\
\text { uncorrected }\end{array}$ & $\begin{array}{l}R \\
\text { corrected }\end{array}$ & $\begin{array}{l}R \\
\text { uncorrected }\end{array}$ & $\begin{array}{l}R \\
\text { corrected }\end{array}$ & $\begin{array}{l}R \\
\text { uncorrected }\end{array}$ & $\begin{array}{l}R \\
\text { corrected }\end{array}$ \\
\hline Mean & 115.32 & 90.72 & 88.14 & 79.18 & 165.32 & 143.04 & 76.81 & 68.91 & 44.94 & 41.03 \\
\hline SD & 95.12 & 73.30 & 77.07 & 59.04 & 123.09 & 121.99 & 54.34 & 52.61 & 34.61 & 32.02 \\
\hline$n$ & 35 & 35 & 35 & 35 & 35 & 35 & 35 & 35 & 35 & 35 \\
\hline Min & 7.21 & 5.67 & 7.44 & 6.48 & 16.84 & 10.97 & 3.34 & 8.71 & 8.28 & 8.24 \\
\hline Max & 364.03 & 267.29 & 327.72 & 238.81 & 577.79 & 511.22 & 231.11 & 222.51 & 135.54 & 138.27 \\
\hline Test value & \multicolumn{2}{|l|}{1.684} & \multicolumn{2}{|l|}{1.704} & \multicolumn{2}{|l|}{1.677} & \multicolumn{2}{|l|}{1.067} & \multicolumn{2}{|l|}{1.168} \\
\hline$F$ value & \multicolumn{2}{|c|}{1.772} & \multicolumn{2}{|l|}{1.772} & \multicolumn{2}{|l|}{1.993} & \multicolumn{2}{|l|}{1.772} & \multicolumn{2}{|l|}{1.841} \\
\hline Significance & \multicolumn{2}{|c|}{ Randomly different } & \multicolumn{2}{|c|}{ Randomly different } & \multicolumn{2}{|c|}{ Randomly different } & \multicolumn{2}{|c|}{ Randomly different } & \multicolumn{2}{|c|}{ Randomly different } \\
\hline
\end{tabular}

Note that the variances of distributions from the mean values corrected to $37^{\circ} \mathrm{C}$ do not differ significantly from those of the uncorrected values yet there is a slight decrease of standard deviation in all organs/tissues corrected to $37^{\circ} \mathrm{C}$

T1 temperature dependence [35]. In forensic practice, corpses are examined with temperatures usually ranging between 0 and $40{ }^{\circ} \mathrm{C}$. To compare synthetic MRI quantitative data from different corpse scans, the temperature dependence of the quantitative values has to be taken into account. A valid comparison of different MRI scans is possible only when the quantitative values gained from the scans are corrected for the temperature. Therefore, the temperature-induced differences between individual corpses can be equalized. Comparison of the T1 and T2 values from the present study that were corrected to $37{ }^{\circ} \mathrm{C}$ with in vivo $\mathrm{T} 1$ and $\mathrm{T} 2$ relaxation times for 3-T applications collected from the literature showed that our ex vivo values are within the range of the known in vivo values [23-27]. Therefore, if quantitative values are corrected to $37{ }^{\circ} \mathrm{C}$, diagnostic criteria developed from the data of postmortem quantitative MRI scans may also be applied for detection of pathologic tissue in living patients [16-21]. In the present study equations to correct for the temperature dependence of T1, T2 and PD to $37^{\circ} \mathrm{C}$ were introduced. As a result of correcting quantitative values to $37^{\circ} \mathrm{C}$, standard deviations especially of the $\mathrm{T} 1$ values decreased in all organs. Those decreases were not significant in the $F$ test. This, however, may be explained by the fact that the standard deviations per se also represent the individuals tissue compositions, e.g. in fatty and non-fatty livers. Also correction of quantitative values to $37{ }^{\circ} \mathrm{C}$ resulted in a statistically better discrimination between the examined organs and tissues which proves the need for temperature correction.

To the best of our knowledge the proton density (as percentage) has not previously been evaluated in vivo for quantification of thoraco-abdominal organs in 3-T applications. In the present study the PD values were a suitable parameter to quantify and characterize tissues. Thus, use of the PD for tissue characterization in vivo may also be promising.
A 3-T MRI system was used for the present study. Given that the relaxation behaviour of tissues is influenced by the magnitude of the magnetic field, it is to expect that the use of MRI scanners with different magnetic field strengths, such as $1.5 \mathrm{~T}$, will result in different quantitative values for T1 and T2 for the same tissue and temperature [35]. Quantitative values of relaxation times should therefore be adapted not only to different temperatures but also to different magnetic field strengths.

Another aspect that has to be taken into consideration is that different tissue temperatures influence not only the quantitative relaxation times but also the image contrast. In preliminary studies, the scanning sequences used and optimized for the living did not work comparably on human corpses. In particular, the routinely established T1-weighted images were often of low contrast when applied on corpses as a result of the strong temperature dependence of the spin-lattice relaxation $[6,36]$. To demonstrate the true potential of MRI in postmortem non-invasive diagnostics, the sequences have to be adapted and optimized in consideration of the corpse core temperature at the time of imaging. The imaging parameters of the widely used T1, T2 and PD weighted images need to be optimized for normal corpse temperatures ranging from 0 to $40{ }^{\circ} \mathrm{C}$.

The present study has several limitations. Data were obtained from only 35 cases. In order to create a database with regular quantitative $\mathrm{T} 1, \mathrm{~T} 2$ and $\mathrm{PD}$ values for different organs, higher case numbers are required. Another limitation is that the investigated organs and tissues were not examined histologically. Quantitative values of organs might have been influenced by histologically evident pathologies not visible in the synthetically calculated MRI images. For example, liver steatosis that was not visible in the MRI images but histologically evident might have affected the quantitative values of the liver tissue leading to a greater range of the standard 
deviations. Furthermore only one quantification set was acquired per corpse at one certain temperature. No corpse was examined at different temperatures. This and low case numbers may have affected the accuracy of the equations introduced for temperature/quantitative value relations. Further studies are required to improve the correlation between changing temperatures and quantitative tissue values. Thus, the same objects should be scanned at different temperatures ranging from 0 to $40{ }^{\circ} \mathrm{C}$; then, more accurate equations to correct for the temperature dependences may be introduced.

\section{Conclusion}

Postmortem MR quantification using a combination of the relaxation times of T1, T2 and the value for PD allows for soft tissue discrimination. The application promises to open a new horizon in characterizing normal and pathologic soft tissue based on MRI images in an objective manner. Further studies are required to reveal the diagnostic possibilities and limits of postmortem synthetic MRI soft tissue analysis. The temperature dependence of the $\mathrm{T} 1$ values and the differing core temperatures of corpses challenge the application of MR quantification. Equations to correct for the temperature dependence at $3 \mathrm{~T}$ have been introduced.

Acknowledgements The scientific guarantor of this publication is Prof. Christian Jackowski MD, Head of Department, Institute of Forensic Medicine, Bern/Switzerland. The authors of this manuscript declare no relationships with any companies whose products or services may be related to the subject matter of the article. The authors state that this work has not received any funding. Beat Kneubuehl, $\mathrm{PhD}$, kindly provided statistical advice for this manuscript. Institutional review board approval was not required because all cases/corpses were investigated by order of the local prosecutors. The prosecutors agreed to research on corpses when the personal data of the deceased persons are treated as strictly confidential. Since we treat all personal data of corpses as confidential we have information from the institutional review board that approval from the review board is not necessary for all our conducted postmortem studies including postmortem imaging. Written informed consent was not required for this study because the subjected studies were deceased persons. None of the study subjects or cohorts have been previously reported. Methodology: prospective, experimental, performed at one institution.

\section{References}

1. Patriquin L, Kassarjian A, Barish M et al (2001) Postmortem wholebody magnetic resonance imaging as an adjunct to autopsy: preliminary clinical experience. J Magn Reson Imaging 13:277-287

2. Roberts IS, Benbow EW, Bisset R et al (2003) Accuracy of magnetic resonance imaging in determining cause of sudden death in adults: comparison with conventional autopsy. Histopathology 42:424-430

3. Dirnhofer R, Jackowski C, Vock P, Potter K, Thali MJ (2006) VIRTOPSY: minimally invasive, imaging-guided virtual autopsy. Radiographics 26:1305-1333

4. Lundström C, Persson A, Ross S et al (2012) State-of-the-art of visualization in post-mortem imaging. APMIS 120:316-326
5. Jackowski C, Thali MJ, Buck U et al (2006) Noninvasive estimation of organ weights by postmortem magnetic resonance imaging and multislice computed tomography. Invest Radiol 41:572-578

6. Jackowski C, Thali MJ, Aghayev E et al (2006) Postmortem imaging of blood and its characteristics using MSCT and MRI. Int J Legal Med 120:233-240

7. Fitzmaurice GJ, Wishart V, Graham AN (2013) An unexpected mortality following cardiac surgery: a post-mortem diagnosis of cardiac amyloidosis. Gen Thorac Cardiovasc Surg 61:417-421

8. Aghayev E, Sonnenschein M, Jackowski C et al (2006) Postmortem radiology of fatal hemorrhage: measurements of cross-sectional areas of major blood vessels and volumes of aorta and spleen on MDCT and volumes of heart chambers on MRI. AJR Am J Roentgenol 187: 209-215

9. Kuroiwa Y, Yamashita A, Nishihira K et al (2011) Cardiac rupture in acute myocardial infarction: post-mortem MR imaging. Magn Reson Med Sci 10:255-258

10. Jackowski C, Christe A, Sonnenschein M, Aghayev E, Thali MJ (2006) Postmortem unenhanced magnetic resonance imaging of myocardial infarction in correlation to histological infarction age characterization. Eur Heart J 27:2459-2467

11. Jackowski C, Warntjes MJ, Berge J, Bar W, Persson A (2011) Magnetic resonance imaging goes postmortem: noninvasive detection and assessment of myocardial infarction by postmortem MRI. Eur Radiol 21:70-78

12. Thayyil S, Sebire NJ, Chitty LS et al (2013) Post-mortem MRI versus conventional autopsy in fetuses and children: a prospective validation study. Lancet 382:223-233

13. Jackowski C, Hofmann K, Schwendener N, Schweitzer W, KellerSutter M (2011) Coronary thrombus and peracute myocardial infarction visualized by unenhanced postmortem MRI prior to autopsy. Forensic Sci Int 214:e16-e19

14. Jackowski C, Schweitzer W, Thali MJ et al (2005) Virtopsy: postmortem imaging of the human heart in situ using MSCT and MRI. Forensic Sci Int 149:11-23

15. Jackowski C, Schwendener N, Grabherr S, Persson A (2013) Postmortem cardiac $3 \mathrm{~T}$ magnetic resonance imaging: visualizing the sudden cardiac death? J Am Coll Cardiol 62:617-629

16. Warntjes JB, Dahlqvist O, Lundberg P (2007) Novel method for rapid, simultaneous $\mathrm{T} 1, \mathrm{~T}^{*} 2$, and proton density quantification. Magn Reson Med 57:528-537

17. Warntjes JB, Leinhard OD, West J, Lundberg P (2008) Rapid magnetic resonance quantification on the brain: optimization for clinical usage. Magn Reson Med 60:320-329

18. Warntjes MJ, Kihlberg J, Engvall J (2010) Rapid T1 quantification based on 3D phase sensitive inversion recovery. BMC Med Imaging 10:19

19. Blystad I, Warntjes JB, Smedby O, Landtblom AM, Lundberg P, Larsson EM (2012) Synthetic MRI of the brain in a clinical setting. Acta Radiol 53:1158-1163

20. Jackowski C, Warntjes MJ, Kihlberg J, Berge J, Thali MJ, Persson A (2011) Quantitative MRI in isotropic spatial resolution for forensic soft tissue documentation. Why and how? J Forensic Sci 56:208-215

21. Vågberg M, Lindqvist T, Ambarki K et al (2013) Automated determination of brain parenchymal fraction in multiple sclerosis. AJNR Am J Neuroradiol 34:498-504

22. Synthetic MR (2014) http://www.syntheticmr.com. Accessed 30 Mar 2014

23. Liu CY, Bluemke DA, Gerstenblith G et al (2014) Reference values of myocardial structure, function, and tissue composition by cardiac magnetic resonance in healthy African-Americans at 3T and their relations to serologic and cardiovascular risk factors. Am J Cardiol 114:789-795

24. von Knobelsdorff-Brenkenhoff F, Prothmann M, Dieringer MA (2013) Myocardial T1 and T2 mapping at 3 T: reference values, 
influencing factors and implications. J Cardiovasc Magn Reson 15: 53

25. Bazelaire C, Duhamel GD, Rofsky NM, Alsop DC (2004) MR imaging relaxation times of abdominal and pelvic tissues measured in vivo at $3.0 \mathrm{~T}$ : preliminary results. Radiology 230: 652-659

26. Ding Y, Mason RP, McColl RW et al (2013) Simultaneous measurement of tissue oxygen level-dependent (TOLD) and blood oxygenation level-dependent (BOLD) effects in abdominal tissue oxygenation level studies. J Magn Reson Imaging 38:1230-1236

27. Pai A, Li X, Majumdar S (2008) A comparative study at $3 \mathrm{~T}$ of sequence dependence of $\mathrm{T} 2$ quantitation in the knee. Magn Reson Imaging 26:1215-1220

28. Ljung P, Winskog C, Persson A, Lundström C, Ynnerman A (2006) Full body virtual autopsies using a state-of-the-art volume rendering pipeline. IEEE Trans Vis Comput Graph 12:869-876

29. Persson A, Lindblom M, Jackowski C (2011) A state-of-the-art pipeline for postmortem CT and MRI visualization: from data acquisition to interactive image interpretation at autopsy. Acta Radiol 52:522536
30. Dickinson RJ, Hall AS, Hind AJ, Young IR (1986) Measurement of changes in tissue temperature using MR imaging. J Comput Assist Tomogr 10:468-472

31. Wlodarczyk W, Hentschel M, Wust P et al (1999) Comparison of four magnetic resonance methods for mapping small temperature changes. Phys Med Biol 44:607-624

32. Peller M, Kurze V, Loeffler R et al (2003) Hyperthermia induces T1 relaxation and blood flow changes in tumors. A MRI thermometry study in vivo. Magn Reson Imaging 21:545-551

33. Parker DL, Smith V, Sheldon P, Crooks LE, Fussell L (1983) Temperature distribution measurements in two-dimensional NMR imaging. Med Phys 10:321-325

34. Youl BD, Hawkins CP, Morris JK, DuBoulay EP, Tofts PS (1992) In vivo $\mathrm{T} 1$ values from guinea pig brain depend on body temperature. Magn Reson Med 24:170-173

35. Haacke ME, Brown RW, Thompson MR, Venkatesh N (1999) Magnetic resonance imaging-physical principles and sequence design. Wiley, New York

36. Ruder TD, Hatch GM, Siegenthaler L et al (2012) The influence of body temperature on image contrast in post mortem MRI. Eur J Radiol 81:1366-1370 